\author{
Karen Mary Giffin \\ Escola Nacional de Saúde Públic a Sérgio Arouca \\ Fundação Oswaldo Cruz
}

\title{
Produção do conhecimento em um mundo "problemático": contribuições de um feminismo dialético e relacional
}

\begin{abstract}
Resumo: Este artigo aborda a vanços na epistemologia feminista que partira m da consta tação da natureza androcêntrica da ciência binária, para desvelara relação de constituição mútua entre os sujeitos da ciência e o conhecimento que produzem. Essa percepção, que abriu a possibilida de de combater a ciência determinista e binária atra vés de a nálise da produção do conhecimento como processo social e histórico, ta mbém revelou a natureza ideologiza da do mundo social. São a presentadas autoras que constroem uma perspectiva crítica, dia lética e relacional que visa a iluminar como 'diferenças' são articuladas em relações sistêmicas de dominação e a transformar este mundo 'problemático'.

Palavras-chave: epistemologia feminista; estudos sociais da ciência; ideologia; dialética.
\end{abstract}

Copyright × 2006 by Revista Estud os Feministas.

${ }^{1}$ Fritjof CAPRA, 1995; e Boaventura SANTOS, 1994.

\footnotetext{
${ }^{2}$ Neste trabalho, 'dominação' é entendida dessa forma, na articulação de múltiplas facetas de diferença.
}

${ }^{3}$ Dorothy SMITH, 1987.

\section{Introdução}

O questionamento do paradigma epistemológico domina nte (ou a 'crise da ciência') é um processo histórico complexo com muitas contribuições. ${ }^{1}$ Este artigo visa a apresentar uma perspectiva feminista específica sobre a construção do conhecimento que, embora compartilhe a spectos da crític a à c iência positivista com muitas outras vertentes teóricas, se distingue pela sua insistência em relacionar as rea lida des loca is/c otidia nas - incluindo aí as a tivida des teóric as de feministas - com rela ções sistêmic as de dominação que articulam, mas extra polam, as relações de gênero. ${ }^{2}$

As dific ulda des desse empreend imento sã o refletidas na caracterização do mundo cotidiano como "problemático"3 e um conceito crítico de "ideologia" é 
${ }^{4}$ HARAWAY, 1994, p. 258.

centraliza do para avançar na compreensão da relação dialética, de determinação mútua, entre o simbólico e o material, e entre o subjetivo e o objetivo, na conformação da dominação e sua superação.

Essa perspectiva rejeita os termos de uma discussã o binária e abstrata de 'igualdade/diferença' no feminismo, e alerta para o perigo da sua cumplicidade com o aprofundamento da dominação e exclusão que ocorre, hoje, interna ciona Imente. Naspala vras de Donna Hara way, "Algumas diferenças são divertidas; outras representam pólos de sistemas históricos mundia is de dominação. A 'epistemologia' se encarrega de fazer-nos conhecer a diferença". ${ }^{4}$

\section{Construção social de uma epistemologia contra-hegemônica}

O movimento de mulheres, opondo-se à caracterização binária de homens e mulheres como seres essencialmente diferentes, com lugares diferenciados e poderes desiguais na sociedade, almejou um autoconhecimento e uma transformação do lugar das mulheres: uma proposta de saber e poder. Nesse movimento, nomear nossa própria op ressão foi um ato de poder e uma contestação do esquema binário vigente, uma a firmação de que seríamos capazes de transformar esta ordem social. Esse sujeito oprimido - tanto dominado como tendo o poder da contestação - é um sujeito nãobinário por excelência.

No feminismo, a crític a partiu de uma práxis em grupos de reflexão (consciousness-raising) que antecederam os estudos da ciência no âmbito acadêmico. Nos grupos de reflexão problematizamos nosso cotidiano, em uma forma alternativa de construir conhecimento: coletivamente, e a partir das nossas próprias experiências, inclusive as ma is íntimas nas relações com homens. Apesar de nossas diferenças individua is, nesse processo coletivo encontra mos muita scomunalidades, o que fa voreceu uma forte sensação de que a identidade feminina, o ser mulher, é uma construção social, e implicada em poderes desigua is. Este foi o primeiro passo: recusando os termos dessa construção, inauguramos um movimento contra-hegemônico.

Ao mesmo tempo, muitas das nossas experiênciase nossos sentimentos não correspondiam ao que, em princípio, se esperava e se dizia das mulheres (fazemos abortos, por exemplo). Começamos a perceber o silêncio sobre essas questões como uma importante forma de controle social, na qual éramos todas implicadas, e anunciamos: 'O pessoal é político!' Entender as razões de 
${ }^{5}$ Ver, entre muitíssimos, Sandra HARDING, 1986; e Evelyn KEUER e Helen LONGINO, 1996.

\begin{abstract}
${ }^{6}$ Boaventura de Souza dos Santos considera que uma transição paradigmática, como esta que atualmente se processa, implic a sempre uma nova visão da subjetividade e do conhec imento (SANTOS, 1994).
\end{abstract}

${ }^{7}$ Sondra FARGANIS, 1997, p. 228. a nossa opressão ser, a té então, invisível, no entanto, demandaria o uso de teoria que revela porque o cotidiano não é transparente.

A investigação do lugar das mulheres na ciência, esfera legitimada da produção do conhecimento, revelou tanto a ampla extensão dos fundamentos binários dessa c iência qua nto a invisibilidade das mulheres como sujeitos dela. Como objetos da ciência, fomos definidas não somente como diferentes dos homens, mas ta mbém como biologicamente inferiores e, entre outras coisas, ina dequadasa o exercício do papel de cientista. Isso levou à caracteriza ção dessa ciência como androcêntrica, permitindo vislumbra ruma relação de constituição mútua entre o sujeito masculino e o seu conhecimento: definindo a mulher como inadequada para a ciência, definia a si mesmo, assegurando seu próprio poder. ${ }^{5}$

Sob essa perspectiva, a idéia da 'objetividade' científica e da 'neutralidade' do sujeito do conhecimento, que seriam garantidas a través do 'método científico', envolveu uma negação da ação dos sujeitos no mundo social: enquanto os sujeitos do cotidiano não são reconhecidos como participantes da produção do conhecimento e da construção da realidade social, o sujeito científico seria 'neutralizado' a través das regras científicas.

A legitimação da ciência binária como âmbito de construção do conhecimento 'objetivo e universal' foi desmascarada: engajados na re/produção de poderes, essa ciência e seu sujeito se re/presentam como 'desinteressa dos'. A partir desse entendimento, instituímos uma política explícita do conhecimento, para contestar 0 entendimento binário - tanto do 'ser' como do 'conhecer'. ${ }^{6}$

\section{Críticas dialéticas à ciência binária/ objetivista/positivista: parte integrante de sistemas de poder e dominação}

Da perspectiva que entende o social como estruturado historicamente pela articulação de diferenças em relações de dominação sistêmicas, emergem questões tais como: quem se beneficia de uma visão da natureza como objeto a ser dominado? Usamos o conhecimento para dar continuidade aos atuais arranjos de divisões sociais, ou para eliminar distinções de classe? Usamos o conhecimento para confirmar padrões de subordinação ou para tomar válidas propostas de equidade de gênero ou de justiça social??

Ruth Berman observa que a ciência objetivista, a lém de postular a divisão sujeito/objeto, 
${ }^{8}$ BERMAN, 1997, p. 254.

${ }^{9}$ BERMAN, 1997, p. 258.

${ }^{10}$ Num exemplo recente, O Globo (8.6.2004) noticia, a partir de um estudo com gêmeas: "Infidelidade poderia ter uma origem genética". Na reportagem, gêmeas idênticas são referidas como "clones natura is"! Embora a reportagem inclua comentários lembrando os fatores sociais, a pesquisa não os considera.

11 BERMAN, p. 248.
[...] conceitua liza os fenômenos como compostos de unidades elementares discretas, individuais, sendo o todo constituído pelo conjunto desses elementos separados. Além disto, presume uma relação linear, quantitativa, de causa e efeito entre os fenômenos. ${ }^{8}$

Nesse modelo, a natureza é concebida como máquina e os processos naturais são abstraídos e convertidos em leis imutá veis.

A concepção dialética da natureza, em contraste, vê toda existência como matéria em movimento, e se preocupa com fenômenos específicos sob condições determinadas, cujo entendimento exige interação entre observador e observado (ou, práxis).

Berman nota que govemos do mundo inteiro se a póiam na ciência binária e sua tecnologia para sustentar seu poder, e que a idéia da máquina como protótipo da natureza parece ter se tornado a ideologia oficial nas sociedades que agora permitem patenteamento de organismos vivos na busca de lucro: "A vitória da máquina sobre a vida nos corredores de nossa estrutura de poder dificilmente poderia serexpressa de forma ma is exp lícita". ${ }^{9}$

Da mesma forma, a ponta que as teorias a tua is da sociobiologia e da microbiologia trabalham com uma concepção binária dos genes e do meio ambiente, na qual os genes são apresentados como os determinantes fundamentais de todo comportamento e patologia humanos. ${ }^{10}$ Isso situa os indivíduos, e não a sociedade, como responsáveis por seus problemas, e nega a necessidade de mudança social.

Observando que essas teorias se empenham persistentemente em demonstrar esses 'determinantes últimos', a pesar das crític as contundentese inca nsá veis que tenham sido feitas, Berman busca as raízes históricas das suas noções binárias. Conclui que, desde os gregos a té a a tua lidade, elas serviram para justificar desigualdades sociais, em sociedades divididas entre dominantes e domina dos. A função política das explicações biologiza ntes fundamenta sua persistência:

[... quando a ciência de uma sociedade é reconhecida como uma expressão da sua ideologia, o repetido ressurgimento em nossa mídia de hipóteses biológicas deterministas [... não constitui ma is um fenômeno misterioso ou aberrante. Representa a maneira de pensarnecessária à preservação de uma sociedade baseada na hegemonia de uma elite. ${ }^{11}$

Donna Wilshire retoma a questão dos binários, observando que, ma is que simples expressão de diferenças, são sempre hierarquizados, "opostos polarizados em que 
${ }^{12}$ WILSHIRE, 1997, p. 102.

${ }^{13}$ WILSHIRE, 1997, p. 117.

${ }^{14}$ WILSHIRE, 1997, p. 107.

${ }^{15}$ GROSZ, 1993, p. 187. Esta e as demais citações de textos em inglês são tra duzidas pela autora. um lado tem domínio sobre o outro"12, sendo úte is na produção do conhecimento que tem porfim lucrar com o controle e a dominação da natureza, a qualquer preço. $\mathrm{Na}$ medida em que os binários, e as imagens a eles associados, tomaram-se uma parte da nossa maneira de pensar, são como lentes a tra vés das qua is contemplamos a realidade social.

Wilshire contrapõe a imagem da natureza como má quina às imagens de mitos pré-históric os centra dos na grande deusa-mãe. Em contraste com os deuses gregos, que foram rep resenta dos como persona lida desind ividua is, mas diferentes das pessoas comuns e da natureza, as imagens da Grande Mãe incorporavam todas as coisas naturais, incluindo o que todos os seres humanos compartilhavam. Relaciona ndo a totalida de, expressa ram uma outra maneira de serno mundo que permite uma outra perspectiva, relacional e holística, no conhecimento: "A imagem da Deusa contém dentro dela uma suposição (pa drão) de tota lida de, de unic idade mente-corpo e terra, de uma maneira não dualista, cooperativa, solíc ita de estar no mundo". 13

Essas imagens, de uma forma não-linear, expressavam e revelavam o movimento dos fenômenos cíclicos naturais, intimamente relacionados a o corpo reprodutivo das mulheres:

[... ] o mito primordial propõe uma maneira de pensare estar no mundo que dissolve o dualismo, neutraliza hierarquias coercitivas e coloca alguns velhos tabus (especialmente sobre o sangue das mulheres e seus corpos com escuros interiores) em novas e positivas perspectivas, criando possibilidades [...] para o conhecimento sobre a natureza humana [...] o signific ado da vida era constituído pela integridade, interconexão e pela experiência cíclica do tempo não por dualismos e linearidade. ${ }^{14}$

Wilshire observa que, desde os gregos, houve na civilização e na filosofia ocidentais uma explícita desvalorização do corpo, o que foi reforçado durante a revolução científic a pela idéia ca rtesiana da produção do conhec imento: penso, logo existo. Nas pala vra s de Elizabeth Grosz,

[...] a crise da razão é conseqüência do privilégio dado, historicamente, ao puramente conceitual ou mental, em detrimento do corporal: isto é [... ] a inabilidade dos conhec imentos ocid enta is em conceber seus próp rios processos de produção (material), processos que simultaneamente são baseadosem, e negam, o papel do corpo. ${ }^{15}$ 
${ }^{16}$ J AG GAR, 1997, p. 158.

${ }_{17}$ J AG GAR, 1997, p. 158.

${ }^{18}$ J AG GAR, 1997, p. 160.

${ }^{19}$ J AG GAR, 1997, p. 161.
Alison Jaggar relabora a idéia de que, no paradigma binário que separa mente/corpo e razão/emoção, o corpo e as emoções têm sido considerados prejudicia is a o conhecimento:

Com o desenvolvimento da ciência modema [...] as esferas da natureza e dos valores foram separadas: a primeira foi despojada de qualquer valor e reconceitua liza da como um mecanismo inanima do sem mérito intrínseco. Os valores foram deslocados para os seres humanos e enraizados em suas preferências e respostas emocionais. A separação entre fatos sup osta mente natura is e os va lores huma nos signific a va que a razão, a fim de poderfomecerum entendimento fidedigno da realidade, deverá ser abstraída desses valores para não ser por eles contaminada. ${ }^{16}$

Essa separação binária impôs, por outro lado, uma reconc eitualização correspondente da emoção como 'impulsos não-racionais', individuais, va riá ve is e idiossincráticos: "[... ] [as emoções] aconteciam a um indivíd uo ou the eram impostas - algo que se sofria em vez de algo que se fazia". ${ }^{17}$

Com a intenção declarada de mostrar que as emoções podem ser úteis ou mesmo necessárias à construção do conhecimento, Jaggar aponta que as emoções têm sido vistas de variadas e inconsistentes maneiras a o longo do tempo, e que o termo abrange uma ampla gama de fenômenos, desde reações reflexivas a té a dedicação por toda a vida a uma causa, desde sensações indiferenciadas de sede ou fome a respostas estética s a Ita mente c iviliza das. llustra, nessa disc ussã o, que o próprio conceito de emoção é uma invenção histórica, uma construção social, que participa "da organização fundamental de nosso modo de olharpara nós mesmos e para os outros". ${ }^{18}$

O positivismo separou a razão das emoções, relegando-as às reações fisiológicas ou movimentos corpora is involuntá rios. Assim, a s emoções não foram vistas como tendo referência a coisa alguma fora delas próprias: "[...] a o contrário, eram vistas isoladamente como fatores potenciais de perturbação de outros fenômenos que são sobre alguma coisa, como julgamentos raciona is, pensamentos e observações". ${ }^{19}$ Essa definição revela-se deficiente: na medida em que equipara as emoções com as sensações e estas são, por definição, percebidas conscientemente, não permite a possibilidade de alguém não estar consciente do seu estado emocional, algo que acontece freqüentemente.

Em concepções ma is recentes, no enta nto, aspec tos cognitivos das emoções têm sido privilegiados, em 
${ }^{20}$ J AGGAR, 1997, p. 162.

${ }^{21}$ J AGGAR, 1997, p. 162.

${ }^{22}$ J AG GAR, 1997, p. 164-165.

${ }^{23}$ J AG GAR, 1997, p. 166.

${ }^{24}$ J AGGAR, 1997, p. 167. definições que enfocam seu aspec to intencional, inc luindo os julga mentos subja centes. Isso permitiu perceberque "[...] os seres humanos se desenvolvem e amadurecem nas emoções assim como em outras dimensões [... ] de a cordo com suas experiências de vida e suas reflexões sobre as mesmas". 20 Embora valorize esse avanço, Jaggar argumenta que as explicações cognitivistas acabam reproduzindo o dualismo, deixando de explicar a relação entre os aspectos cognitivos e afetivos nas emoções:

[...] elas perpetuam a distinção positivista entre o mundo compartilhado, público, objeto de cálculos, observações e fatos verificá veis e o mundo individual, privado, subjetivo de sentimentos e sensações id iossincrátic os. Essa nítida distinção rompe qua isquer vínculos conceitua is entre o que sentimos e o mundo 'extemo'. ${ }^{21}$

Jaggar explicita a importância de reconhecer as emoções como soc ia Imente construídas. Na sua disc ussão, aponta que tendemos a vivenciar nossas emoções como reações involuntá rias e individua is. No entanto, há diferenças culturais marcantes no reconhecimento, nomeação e expressão de emoções, o que revela um processo social subjacente no qual as crianças a prendem o que sua cultura define e conceitua liza como a propria do: “Por essa razão, a s emoções são simulta nea mente torna das possíveise limita das pelos rec ursos conc eitua ise ling üístic os de uma sociedade [...] a experiência individual é simultaneamente experiência social". ${ }^{22}$

Relacionando aspectos corpora is e cognitivos, o sujeito a tivo é visibilizado. As emoções

[... s são trajetórias a tra vés das quais nos engajamos a tiva mente e a té construímos o mundo. Elas têm tanto aspectos mentais como físicos, que se condicionam mutua mente. Em a lguns ca sos, são escolhidas, ma sem outras, são involuntá rias; pressupõem uma linguagem e uma ordem social. Podem sera tribuída sà schama das 'pessoas integrais', engajadas na atividade contínua da vida social. ${ }^{23}$

Essa conceitualiza ção relaciona as emoções humanas dialeticamente com nossa percepção, a través dos valores que permitem julgamentos: "[...] a ssim como a observação direciona, molda e define parcialmente a emoção, a ssim ta mbém a emoção direciona, molda e a té define parcialmente a observação". ${ }^{24}$

Sob essa ótica, as funções políticas do 'mito da investigação imparcial' são reveladas. Como a razão tem sido associada a membros de grupos dominantes, esse mito funciona para re/produzir sua a utoridade epistêmica 
${ }^{25}$ J AG GAR, 1997, p. 172

${ }^{26}$ JAG GAR, 1997, p. 176.

27 J AGGAR, 1997, p. 179.

${ }^{28}$ MACKINNON, 1989, p. 40. exc lusiva: "[...] o ideal do investiga dor imparcial é, portanto, um mito classista, racista e, sobretudo, masculinista". ${ }^{25}$

Como o sujeito é a tivo na sua relação com o mundo, no entanto, Jaggar lembra que podem existir 'emoções proscritas' - reações a injustiças, ou que expressam algo sobre a situação dos subalternos. Examinar essas emoções pode serútil no desenvolvimento de uma perspectiva crític a sobre o mundo: "Podem nos ajudar a compreender que o que foi geralmente considerado como fato foi construído de maneira a obscurecer a realidade de pessoas subordinadas". 26 Dado que há uma interaçã o continuada entre a forma como compreendemos o mundo e quem somos enquanto pessoas, investigar essas emoções pode ser subversivo, polític a e epistemologicamente.

Onde não há separação sujeito/objeto, a autoreflexividade é, igualmente, parte necessária do processo teórico:

a reconstrução do conhecimento é inseparável da reconstrução de nós mesmos [... ]uma parte nec essária do processo teórico é o auto-exame crítico [...] A reflexão crítica sobre as emoções não é um substituto auto-indulgente da análise e ação políticas. É ela mesma uma espécie de teoria e prática política ind ispensá vel para uma teoria social a dequada e para a transformação social.27

Apesar de esse processo ter produzido um novo sujeito feminino (não-binário) do conhecimento (nãobinário), os velhos há bitos binários continuam a se infiltrar (como Berman nos alerta) mesmo no que parece ser o consenso maior nos estudos de gênero - sua construção social. Se o conceito de 'gênero', elaborado para se opor à determinação biológica, quer dizer que a biologia está excluída dessa construção, encamamos o dualismo, re/ produzimos o binário do biológico/social como pólos estanques e opostos, e nos aproximamos perigosamente da velha idéia da mente cartesiana, que se separa do corpo e das emoções, vistos como fontes de perturbação no conhecimento.

Contradições no feminismo, na forma de conceber a relação indivíduo/social nessa construção, são também de importância crucial. No argumento de Catharine MacKinnon, enquanto o feminismo liberal reduz o social a uma coleção de indivíduos, o feminismo radical reduz os indivíduosao social. ${ }^{28}$ Uma outra forma de veressa relação fundamenta a epistemologia dialética em foco aqui, e é explicitada na sociologia compreensiva e no feminismo marxista, dialético: os indivíduos e a realidade social são mutuamente construídos; os sujeitos são tanto construíd os 
29 Entre os mais influentes, Foucault, Derrida e Lyotard. Coerente com a perspectiva a presentada, é preciso dizerque há múltiplos entendimentos do pós-modemo, assim como uma complexidade imensa nas categorizações tanto de idéias como de autores; mas isso não quer dizer que nada se pode conhecer sobre esse assunto, inclusive como fenômeno histórico. Entre os livros que se concentram no debate feminismo/posmodernismo, ver: Marianne HIRSH e Evelyn KELER, 1990; Linda NICHOLSON, 1990; Susan HECKMAN, 1990; Michèle BARRETT e Anne PHILIPS, 1992; Rosemary HENNESSY, 1993; Kathleen LENNON e Margaret WHITFORD, 1994; Seyla BENHABIB, J udith BUTLER, Drucilla CORNELL Nancy FRASER, 1995; e Kathi WEEKS, 1998.

${ }^{30}$ Susan STRIC KLAND, 1994, p. 266

${ }^{31}$ Ca rol STABILE, 1999.

32 Donna HARAWAY, 1988; Susan BORDO, 1993; Susan STRIC KLAND, 1994.

33 Frances MASC IA-LEES, Patricia SHARPE e Colleen COHEN, 1989. historic a mente como construtores na/da realidade social, seja na ciência, seja na vida cotidiana.

As persistentes ou a té cresc entes contra dições no(s) feminismo(s) evidenciam que tornar-se sujeito do conhecimento não resolve a questão de divergências teóricas - antes a instaura. A sensa ção de identida de, que deu impulso para o movimento de mulheres, está agora em questão - não menos porque o feminismo tem convivido durante décadas com um processo g lobal de polarização de classes e nações, ou seja, de aprofundamento das diferenças entre as mulheres. Nossa identidade contrahegemônica revela seus limites: baseada naquilo que não quería mos, contém, ma soculta, contra dições, dific ulta ndo nossa ação política conjunta.

\section{Críticas dialéticas a o pensamento pós- modemo}

No processo de elaboração da crítica, o debate feminista se viu inundado pordiscussões a cerca de autores que representam, na academia, o pensamento 'pósmodemo', 29 a qui entendido em termos gera is como uma celebração de diferença, parcialidade e multiplicidade que afirma a incomensurabilidade de experiências e perspectivas: "A crítica pós-moderna vai além do reconhecimento da natureza histórica da parcialidade e do caráter situado do pensamento humano, para insistir que a justific ação e legitima ção são interna sa uma prática, [ou] jogo de linguagem". ${ }^{30}$ Em conseqüência, "[...] o social é desmonta do e tra nsforma do no 'd isc ursivo', e a srelações socia is, em padrões ling üístic os. Ao defenderasdiferenças, relações individualizadas de poder são enfatizadas, com exclusão de sua interc onexão sistêmic a". ${ }^{31}$

$\mathrm{Na}$ medida em que insista nessa 'relatividade absoluta' de posições, esse complexo de idéias pode ser considera do o 'outro' da ciência positivista. ${ }^{32}$ Nesse sentido, o postulado pós-moderno do sujeito - fluido, plural ou fragmenta do - representa o perfeito reflexo binário do velho sujeito universal, e servindo à mesma função mistific a dora. Paralisado pela sua visão de infinitas e incomensuráveis diferenças entre sujeitos, nega a possibilidade de produção do conhecimento.

Enfoc ando essa relativização de toda verda de como fenômeno histórico, feministas preocupadas com as relações sistêmicas de dominação notaram que o pensamento pós-moderno "[...] tende a negar o status ontológico do sujeito justamente no momento em que as mulheres e os povos não-ocidenta is começaram a se colocar como sujeitos". ${ }^{33}$ 
${ }^{34}$ J AGGAR e BORDO, 1997, p. 13.

35 No original, "accountable." 36 HARAWAY, 1988, p. 583; ver também Helen LONGINO, 1990, p. 212.

${ }^{37}$ Heidi GOTTFRIED, 1996, p. 14.
Opondo-se a essa a bstração rela tivista está a visão da ciência como um empreendimento inteiramente social, de interp retações a tivas realizadas por sujeitos situa dos social e historica mente, e autoriza das por uma coletivida de; uma concepção do sujeito do conhecimento como histórico e social, "[...] corporific a do, interessa do, emocional e racional, e cujo corpo, interesses, emoções e razão são fundamenta Imente constituídos por seu contexto históric o partic ula r". ${ }^{34}$

Em função disso, a 'objetividade' também é dra stic a mente refo rmula da. Agora, "[... ] refere loc a liza ção limitada e conhecimento situado, não transcendência e divisão entre sujeito e objeto. Isto permite que nós nos to memos responsá veis ${ }^{35}$ por aquilo que aprendemos a perceber". 36

Não sendo possível isolar o sujeito do objeto, a separação ciência/sociedade e ciência/política também não se sustenta. Ao contrário, nessa nova visão da objetividade, que reconhece os sujeitos do conhecimento como ativos, portadores de valores e situados em hiera rquia s socia is, a étic a e a polític a são revela das como inerentes à construção do conhecimento - seja isso reconhecido ou não.

A visão do papel político do intelectual é consideravelmente modific a da com isso. Atuarcomo sujeito ético e político do conhecimento interessado exige, portanto, uma postura a uto-reflexiva, pois, se a neutralida de é impossível, quem não toma posição favorecerá a reprodução do status quo, da dominação existente.

Os conhecimentos socialmente situados e parcia is do feminismo dia létic o e relacional se oferecem para serem julgados como instrumentos de ações práticas a serviço de interesses declarados, na produção de conhecimentos sempre históricos e provisórios. Sua relação estreita com a proposta de transforma ção permite evita $r$ o limbo ético do relativismo a bsoluto, que afirma o predomínio absoluto das diferenças e a impossibilidade de um novo pacto social, baseado em entendimentos coletivos sobre valores, na construção de uma nova utopia. Nesse sentido, "Conceitos como 'conhecimentos situados' se opõem, por um lado, à fé modemista não-crítica na razão e na racionalidade e, por outro lado, à rejeição pós-modema da possibilidade do conhecimento". ${ }^{37}$

\section{Investiga ções socia is e práticas conceitua is em um mundo problemático}

Dorothy E. Smith, desde os anos 1970, discute "[...] as práticas conceitua is do poder" típicas das "relações de 
${ }^{38}$ No original, "rela tions of ruling" (SMITH, 1987, p. 3) .

${ }^{39}$ SMITH, 1974 e 1987. mando"38 na sociedade capitalista atual, onde a mercantilização constitui novos espaços de relações socia is, processos ideológicos/informaciona is são de importância crescente na reprodução da ordem social, e uma forma de consciência 'objetificante' e 'textual', típica da produção científica, se disseminou, tornando-se hegemônica..$^{39}$

Nessa s prá tic a s c onc eitua is instituc io na liza das, o a to de conhecer inicia-se de um arcabouço conceitual abstrato que expressa o ponto de vista dos dominantes. A perspectiva e o conhecimento dos atores socia is no cotidiano são excluídos dessas práticas conceituais, a o mesmo tempo que são limitados pelas mesmas. Isso leva a um hia to entre as vivências e os meios dominantes de expressá-las:

[... ]a feitura e disseminação dasformas de pensa mento que usamos para pensar sobre nós mesmos e nossa sociedade fazem parte das relações de mando, tendo origem, portanto, em posições de poder [... ] existe um hiato entre onde nós estamos e os meios que temos para expressare agir. ${ }^{40}$

A consciência, nesses termos, é um produto social, cujas formas são modifica dascom a mudança nas relações socia is que as constituem.

Se considera mosas id eologias de gênero como parte das idéias dominantes, a ceitá-las pode, por exemplo, dificultar a percepção da importância do trabalho doméstico das mulheres, deixando a impressão de que elas são dependentes dos maridos, embora a organização do trabalho deles e a ma is-valia do seu empregador também se beneficiem desse trabalho feminino invisível. Nomeá-las como 'donas de casa', certamente, ajudou a ocultar, durante muito tempo, as sua s própria sa tividades de geração de renda, inclusive nos dados de censos e na própria representação: 'sou apenas uma dona de casa'. A idéia dos homens como 'chefes da casa' continua a produzir dados censitánios nos qua is é quase impossível encontrar mulheres 'c hefes de fa mília' enquanto houvera lgum homem residente, independentemente da sua renda e autoridade na casa. Certamente, idéias dominantes sobre a 'emocionalidade' das mulheres foram importantes, durante muito tempo, em as afastar ou não as reconhecer como sujeitos da ciência. Isso exemplifica a necessidade de nomea ressa rea lid a de social como "problemática": é construída ideologicamente, dificultando a percepção da relação entre a vivência no cotidiano e os processos sistêmicos que reproduzem a desigualdade; é conivente com os interesses dos dominantes em perpetuar esse status quo. 
${ }^{41}$ SMITH, 1990, p. 39

${ }^{42} \mathrm{SMITH}, 1990$, p. 39

43 John THOMPSON, 1999 explicita as várias vertentes do conceito de ideologia, o que ele, como Smith, considera de importância crescente em face do imenso poder dos meios de comunicação de massa na produção e disseminação de formas simbólic as, a tua Imente. Ambos se preocupam, em primeiro lugar com as conseqüências bem materia is das ideologias. ${ }^{44}$ Ver, no Bra sil, Heleieth SAFFIOT, 1993; Ma ry CASTRO, 2000; Regina SIMÕES BARBOSA, 2001, entre outras.

${ }^{45}$ SMITH, 1990, p. 40.

${ }^{46}$ BERMAN, 1997, p. 262.
Na sua exposição, Smith ilumina como as práticas conceituais institucionalizadas na sociologia do conhecimento definiram o conceito de ideologia de tal forma a produzirem aquilo que o conceito pretendia denunciar: a mistifica ção interessa da das relações socia is. Nessa definição, os conhec imentos sã o determina dos pela situa ção do conhecedor. "[...] o pensa mento é considera do uma função da situação vital do pensador [... ] a presença do sujeito é redundante [... ] não é um termo nec essá rio na relação" ${ }^{41}$ Essa definição, portanto, deve ser vista, ela mesma, como prática conceitual ideológica, pois obstrui investigação através da primazia dada aos conceitos e sua manipulação, ao mesmo tempo que nega a (historicamente contextualizada) ação dos atores socia is. Típica das práticas conceitua is institucionaliza das das relações de mando, ela nos prende ao nível conceitual, "[...] sup rimindo a presença e funciona mento das relações subjacentes que expressam". ${ }^{42}$

Embora a epistemologia dialética insista que os conhecimentos sempre envolvem interesses, na concepção crítica de ideologia, ideologias expressam idéias a serviço da dominaçã $0 .{ }^{43}$ Nessa função, naturalizam diferenças e desigualdades, ocultando tanto suas raízes sistêmic as como a partic ipação dos sujeitos no cotidiano, ajudando dessa maneira a reproduzir o status quo.

Explicitara ontologia e a teoria relacional marxistas em termos não-binários e não-deterministas tem sido um projeto importante dentro desse feminismo. ${ }^{44} \mathrm{O}$ conceito crítico de ideologia é central a esse entendimento:

Marx descreve o ideal como 'refletindo' o mundo material e este como 'traduzido' pela mente humana em formas de pensamento [... ] as relaçõesque ele assim nomeia não são relações de determinação, são relações de signific ação [...] as relações socia is subjacentes não deteminam como elas podem ser pensadas, mas provêem as condições do sentido dos conceitos que as expressa m. ${ }^{45}$

Berman, como vimos, havia apontado a mesma questão, observando que a posição ma teria lista e dia lética se diferencia da determinista a o enfatizar que o ponto de vista de todos é mediado a tra vés de construções menta is: "Nosso ponto de vista é, portanto, derivado não somente das nossa s cond ições e rela ções ma teria is espec ífic as, mas também da nossa compreensão delas, nossa consciência". ${ }^{46}$ A possibilidade de modificar nossa compreensão tanto pode permitir uma transformação positiva como pode “[...] desmaterializar o sensório, transformando-o, de acordo com a ideologia 
${ }^{47}$ BERMAN, 1997, p. 262.

${ }^{48}$ SMITH, 1987, p. 90.

${ }^{49}$ GORELICK, 1996, p. 31.

${ }^{50} \mathrm{~J}$ oan AC KER, Ka te BARRY e J oke ESSEVELD, 1996, p. 62. contemporânea, numa abstração consistente e mascarar sua fonte original, a experiência material, com uma construção ideológic a". ${ }^{47}$

Preocupada principalmente em fortalecer estudos críticos de mulheres estudando mulheres, Smith dirige-se às c ientistas soc ia is e recomenda que seus estudos deverão começar com o mundo cotidiano e focalizar os atores socia is como conhecedores. No entanto, explicita que o conhecimento já realizado no cotidiano é um ponto de partida, e não de chegada:

Definir o mundo cotidiano como locus de uma problemática [...] não é a mesma coisa que o tomar como objeto de estud o [...] Enfocaro mundo cotidia no como objeto de estudo é o constituir como universo autocontido de investigação. 0 efeito de situar o conhecedor desta forma é separar/divorciaro mundo cotidiano da experiência das relações socia is e econômicas que organizam seu caráter distintivo [...] separamos [o cotidiano] metodologicamente das formas em que é enraizado num contexto socialmente organizado, maior do que pode ser conhecido diretamente $[\ldots]^{48}$

Sherry Gorelick exemplific a essa questão com o estudo clássico de William Whyte Sociedade das esquinas, de 1943, cujos sujeitos eram grupos de homens pobres de Boston. Tomando essa realidade como objeto de estudo, Whyte enfocou e iluminou os padrões de interação e as hiera rquias simbólicas e socia is nos grupos, na sua religião e na sua política. Mas, aponta Gorelick, esses homens de 30 a nos estavam vivendo pelas esquinas por causa do desemprego gerado na grande depressão, o que não era causa do pelos seus padrões de interação, e não poderia serexplica do dentro desses limites. Ela observa que, olhando apenas seus pa drõesde intera ção, poderiam a penasculpar a si próprios, a os outros, às pessoas que conheciam. ${ }^{49}$

Embora situa mos as pessoas como agentes a tivas das suas próprias vidas e, como tais, construtores dos seus mund os socia is, não considera mos esta a tivida de como fenômeno isolado e subjetivo. Melhor, localizamos a experiência individual na sociedade e na história, enraizada num conjunto de relações sociais que produzem tanto as possibilidades como os limites daquela experiência. O que está em questão não é apenas a experiência no cotidiano, mas as relações subjac entes e as conexões entre as duas [instânc ias]. ${ }^{50}$

Isso ilustra, simultaneamente, os limites do conhecimento do cotidiano, assim como o aponta como loc us da possibilidade do re/conhecimento. Nesse sentido, indica a importância de começar com o entendimento (e 
${ }^{51}$ GORELICK, 1996, p. 38.

as emoções) dos sujeitos do cotidiano, relacionando-os com a teoria e conceitos críticos capazes de iluminar as conexões socioeconômicas sistêmicas, reforçando assim a possibilidade de contestação consciente e resistência às formas id eológicas de dominação.

Embora seja esse o primeiro passo na transformaçã o social, Smith insiste que combatera domina ção hoje requer ma is do que uma crític a à sideologias. Podemosconsiderar esse trabalho intelectual crític o como necessá rio, mesmo que não suficiente; da mesma forma, lembrar sempre que nossa teoria e nossos conceitos são produções históricas, que não podem sertratadas como verdades eternas, mas que precisam também serem constantemente referidas à prática, devendo evoluir nesse processo.

Gorelick aponta que, mesmo tendo intenções libertá rias, nem professoras nem pesquisadoras, sozinhas, podem minarseu próprio podersobre a lunose pesquisa dos, por ser este poder enraizado em contextos instituciona is que orga niza $m$ o traba lho a ca dêmic 0 . Nesse tra ba lho, uma proposta de igualdade entre o/a pesquisador e os/as participantes de pesquisas, paradoxalmente, introduz de novo a idéia da investigação desinteressada. Ao seu trabalho, o/a pesquisador/a traz sua situação social, sua cultura, motivação, limitações, ignorâncias, habilidades, recursos, conhecimento de teoria e metodologia, incapacidades aprendidas no processo de socialização nas instituições dominantes, e uma perspectiva 'de fora' que pode tanto ser útil como problemática.

Como pesquisadores/as, podemos lutar para modificar nossas práticas, situando os sujeitos das nossas pesquisas como ativos conhecedores, mas não podemos simplesmente 'dara voz' aosoutros, nem que fosse apenas isso que se quisesse, pois

[... ] sou eu que fiz as perguntas, eu que li as transcrições, eu que seleciono o material para o texto [...] [As] suas palavras, pensamentose emoções são filtra dosa tra vés das seleçõesque faço, com as minhas próprias posturas polític as, minhas próprias (e ca mbiantes) convic çõese contradições. ${ }^{51}$

Por isso, a auto-reflexividade do/a pesquisador/a é essencial em esclarecer tanto sua situação como sua proposta teórica - embora sejam também transformadas no processo da pesquisa, assim como podem modificaros respond entes.

Sob a perspectiva crítica, dialética e relacional do mundo problemático e ideologizado, podemos entender melhorporque, antes dos grupos de reflexão do feminismo, a opressão 'das mulheres' não foi perc ebida. No entanto, 
52 Termo weberiano central, que refere o processo de compreensão, base da sociologia compreensiva.

${ }^{53}$ GORELICK, 1996, p. 40.

${ }^{54}$ GORELICK, 1996, p. 38.

55 E, muito menos, apenas celebrá-las, como tem sido uma tônica recente em 'estudos cultura is' dominantes, inclusive no feminismo e nos estudos de gênero. como sujeitos do conhecimento acadêmico legitimado, instituc iona liza do, Smith observa que nós estamos situa das contra ditoriamente: como mulheres no cotidiano e ta mbém como participantes das práticas conceituais que nos objetific am como mulheres. Como profissionais, isso pode favorecer nossa percepção do hiato entre as formas abstratas dominantes e nossa própria experiência.

No entanto, como nossa situação é socialmente privilegiada, não podemos ser vistas como simplesmente oprimidas. Isso indica que nossa sensação da identidade feminina, baseada na nossa percepção das comunalidades entre as mulheres, também precisa ser sujeita à análise crítica, que alerta que

[... ] a estrutura de opressã o é empecilho para aqueles que estão na posição dominante, o que nos deixa severamente debilitados na nossa habilidade de perceber a opressão em que estamos implicadas; privilégio limita a té nossa habilida de em entendernossas próprias circunstâncias, sem falar em praticar Verstehen ${ }^{52}$ com os oprimidos. ${ }^{53}$

Por isso, referind o-nos tanto a os respondentes como a nós próprios/as como pesquisa dores, precisamos de "[... ] uma ciência social que revele as comunalida des e conflitos sistêmic os das estrutura s ocultas de op ressão, ta nto como são sentidos como são obscurecidos". ${ }^{54}$

Nos estudos de gênero recentes, situados na academia dominada pelas dúvidas pós-modernas, o reconhecimento das diferenças entre mulheres levou a um processo que, no extremo, questionou a existência de tal categoria. Assim como a desconstrução do sujeito do conhec imento universal produziu uma resposta binária que a firma uma plura lida de ou rela tivida de absoluta, negando a possibilidade de conhecimento, a desconstrução da identidade das mulheres levou algumas à afirmação de que existe apenas uma pluralidade absoluta de diferenças, entre e dentro das mulheres.

Mas enfocar apenas as diferenças também não é suficiente, ${ }^{55}$ se partirmos de uma ótica que afirma a existência de relações sistêmicas de desigualda de social, nas quais diferenças de condição não querem dizer ausência de relação, mas sim um arranjo em que os privilégios de algumas dependem da opressão de outras:

Teorizar, portanto, nã o pode ser fragmenta do, porque a realidade não vem em caixinhas separadas. Devemos desvendarnão somente as experiências diferentes de grupos diversos de mulheres mas ta mbém os processos que criam estas diferenças. Devemos delinear como estes processos de opressão - racista, imperialista, 
56 GORELICK, 1996, p. 39; ver ta mbém LENNON e WHITFORD, 1994.

${ }^{57} \mathrm{SMITH}, 1996$, p. 47.

58 SIGNS, 2001.

59 Rosemary HENNESSY e Chrys ING RAHAM, 1997, p. 3.

${ }^{60}$ CAPRA, 1995.

${ }^{61}$ SANTOS, 1994. classista [... ] são conec ta dose deteminam [... ]as vidas de todas e cada uma. ${ }^{56}$

Como acadêmicos, temos agora os meios de entender que nosso trabalho está contextualiza do pela política de classe da suniversidades, que, "[...] como sistema de controle, tem sido partic ula rmente efetivo em assegurar que o conhecimento produzido não seja orientado às necessidades e interesses da massa do povo, mas sim às necessida dese interesses de mando". ${ }^{57}$ Partic ipa mosca da vez ma is das prátic as conceitua is instituc iona liza das, num â mbito universitá rio ca da vez ma is a trela do às necessida des do capita lismo global, o que desestimula o desenvolvimento e uso de teorias críticas que intencionam transforma ções.

Sob uma perspectiva histórica, é possível perceber o(s) feminismo(s) e sua s ativida des teóricas como fenômenos sociais que não são extemos às relações sistêmicas de poder, nem necessariamente opostos aos processos globais, e que podem até servirpara reforçarformas novas de imperialismo. ${ }^{58}$ Sob a perspectiva dastendências globa is atua is, de concentração da riqueza e crescente exclusão que aumentam as diferenças entre as mulheres, recomenda-se que o feminismo

[...] deve também confrontar os investimentos da sua própria classe em recusara conectar sua a nálise a um sistema social global cuja premissa fundante é que a lguma s mulheres são benefic ia da sà custa de outras. ${ }^{59}$

É preciso enfatizar que o avanço na continuada elaboração do novo paradigma epistemológico - que ocorre em todos os campos, segundo Fritjof Capra ${ }^{60}$ - não foi capaz de reverter as tendências dominantes na construção do conhecimento, e que, como observa Santos, o conflito paradigmátic o "é cada vez ma is um conflito social de grupos e interesses organizados". ${ }^{61}$ No processo de globalização neoliberal, que estende as relações que a umentam as desigualdades, precisamos, sim, marc ar nossas diferenças, na relação com os que não são nossos 'idênticos' - no cotidiano da produção do conhecimento.

\section{Referências bibliográ fic as}

AC KER, J oan, BARRY, Ka te, a nd ESSEVELD, J oke. "O bjec tivity and Truth: Problems in Doing Feminist Research." In: GOTTFRIED, Heidi (ed.). Feminism and Social Change: Bridging Theory and Practice. Urbana and Chicago: University of Illinois Press, 1996. p. 60-87.

BARRETT, Michèle, and PHILIPS, Anne. Destabilizing Theory: Contemporary Feminist Debates. Stanford: Stanford University Press, 1992. 
BENHABIB, Seyla, BUTLER, J udith, CORNELL, Drucilla, and FRASER, Nancy. Feminist Contentions: A Philosophical Exchange. New York and London: Routledge, 1995.

BERMAN, Ruth. "Do dualismo de Aristóteles à dialética materialista: a transformação feminista da ciência e da sociedade". In: JAGGAR, Alison; BORDO, Susan (Orgs.). Gênero/corpo/conhecimento. Rio de Janeiro: Rosa dos Tempos, 1997. p. 241-275.

BORDO, Susan. "Feminism, Postmodemism, and Gender Skeptic ism." In: BORDO, S. Unbearable Weight. Berkeley, Los Angeles, London: University of Califomia Press, 1993. p. 215-244.

CAPRA, Fritjof. O ponto de muta ção: a ciência, a socieda de e a cultura emergente. São Paulo: Cultrix, 1995.

CASTRO, Mary G. "Marxismo, feminismos e fe minismo marxista - mais que um gênero em tempos neolib era is". Crític a Marxista, v. 11, p. 98-108, 2000.

FARGANIS, Sondra. "O feminismo e a reconstrução da ciência social”. In: J AGGAR, Alison; BORDO, Susan (Orgs.). Gênero/corpo/conhecimento. Rio de Janeiro: Rosa dos Tempos, 1997. p. 224-240.

GORELICK, Sherry. "Contradictions for a Feminist Method ology." In: GOTTFRIED, Heidi (ed.). Feminism and Social Change: Bridging Theory and Practice. Urbana and Chicago: University of Illino is Press, 1996. p. 23-45.

GOTTFRIED, Heidi. "Introduction." In: G OTTFRIED, Heidi (ed.). Feminism and Social Change: Bridging Theory and Practice. Urbana and Chic a go: University of Illinois Press, 1996. p. 1-22.

GROSZ, Eliza beth. "Bodies and Knowledges: Feminism and the Crisis of Reason." In: ALCOFF, Linda, and POTIER, Eliza beth. Feminist Epistemologies. New York and London: Routledge, 1993. p. 187-216.

HARAWAY, Donna. "Situated Knowledges: The Science Question in Feminism and the Privilege of Partial Perspective." Feminist Studies, v. 14, n. 3, 1988. p. 575599.

"Um ma nifesto para oscyborgs: c iência, tec nologia e feminismo socialista na década de $80 "$ ". In: BUARQ UE DE HOLANDA, Heloisa (Org.). Tendências e impasses: 0 feminismo como crítica da cultura. Rio de Janeiro: Rocco, 1994. p. 243-288.

HARDING, Sandra. The Science Question in Feminism. Itha ca and London: Comell U. Press, 1986.

HEC KMAN, Susan. Gender and Knowledg: Elements of a Postmodern Feminism. Boston: Northeastern University Press, 1990.

HENNESSY, Rosemary. Materialist Feminism and the Politics of Disc ourse. New York: Routledge, 1993. 
HENNESSY, Rosemary, and INGRAHAM, Chrys. Materialist Feminism: A Reader in Class, Difference, and Women's Lives. New York and London: Routledge, 1997.

HIRSC H, Marianne, and KELLER, Evelyn F (eds.). Conflicts in Feminism. New York and London: Routledge, 1990.

JAGGAR, Alison. "Amor e conhecimento: a emoção na ep istemologia feminista". In: JAGGAR, Alison; BORDO, Susan (Orgs.). Gênero/corpo/conhecimento. Rio de Janeiro: Rosa dos Tempos, 1997. p. 157-185.

J AG GAR, Alison; BORDO, Susan. "Introdução". In: J AGGAR, Alison; BORDo, Susan (Orgs.). Gênero/corpo/ conhecimento. Rio de Janeiro: Rosa dos Tempos, 1997. p. 7-16.

KELER, Evelyn, and LONGINO, Helen. Feminism and Science. New York: Oxford University Press, 1996.

LENNO N, Kathleen, and WHITFORD, Marga ret. "Intro duc tion." In: LENNON, Kathleen, a nd WHITFORD, Margaret (eds.). Knowing the Difference: Feminist Perspectives in Epistemology. Lond on and New York: Routledge, 1994. p. 1-16.

LONGINO, Helen. Science as Social Knowledge: Values and Objectivity in Scientific Inquiry. Princeton: Princeton University Press, 1990.

MACKINNON, Catharine. Toward a Feminist Theory of the State. Cambridge and London: Harvard University Press, 1989.

MASC IA-LEES, Fra nces, SHARPE, Pa tric ia, a nd COHEN, Colleen B. "The Postmodem Tum in Anthropology: Cautions from a Feminism Perspective." SIGNS, v. 14, n. 1, 1989. p. 733.

NICHOLSON, Lind a. Feminism/Postmodernism. New York and London, Routledge, 1990.

SAFFIOT, Heleieth I. B. "Novas perspectivas metodológicas de investigação das relações de gênero". In: MORAIS SILVA, Maria Aparecida (Org.). Mulher em seis tempos. Araraquara, SP: Editora da UNESP, 1993. p 141-176.

SANTOS, Boaventura de Souza. Um disc urso sobre a ciência. Lisboa: Edições Afrontamento, 1994.

SIG NS. Editorial, G lobalization and Gender. SIGNS, v. 26, n. 4, 2001. p. 943-948.

SIMÕES BARBOSA, Regina. H. Mulheres, reprodução e aids: as tramas da ideologia na assistência à saúde de gesta ntes hiv-positivas. 2001. Tese (Doutora do em Saúde Públic a ) - ENSP/FIOC RUZ, Rio de J a neiro.

$\mathrm{SMITH}$, Dorothy E. "Women's Perspective as a Ra dic al Critique of Soc iology." Sociological Inquiry, v. 44, n. 1, 1974. p. 7-13.

The Everyday World as Problematic: A Feminist Sociology. Boston: Northea stern University Press, 1987. 
. The Conceptual Practices of Power: A Feminist Sociology of Knowledge. Boston: Northea stem University Press, 1990.

"Contradic tions for Feminist Social Scientists." In: GOTTFRIED, Heidi (ed.). Feminism and Social Change: Bridging Theory and Practice. Urbana and Chicago: University of Illino is Press, 1996. p. 46-59.

STABILE, C a rol A. "Pós-modernismo, feminismo e Marx: notas do a bismo". In: WOOD, Ellen M.; FOSTER, J ohn. B (Orgs.). Em defesa da história. Rio de Janeiro: Zahar, 1999. p. 145-160.

STRIC KLAND, Susan. "Fe minism, Postmodernism and Difference." In: LENNON, Kathleen, and WHITFORD, Margaret (eds.). Knowing the Difference: Feminist Perspectives in Epistemology. London and New York: Routledge, 1994. p. 265-274.

THOMPSON, J ohn B. Ideologia e cultura moderna: teoria crítica social na era dos meios de comunicação de massa. Petrópolis, RJ : Vozes, 1999.

WEEKS, Ka thi. Constituting Feminist Subjects. Comell: Comell University Press, 1998.

WILSHIRE, Donna. "Os usos do mito, da imagem e do corpo da mulher na re-ima gina ção do conhecimento". In: JAGGAR, Alison; BORDO, Susan (Orgs.). Gênero/corpo/ conhecimento. Rio de J a neiro: Rosa dos Tempos, 1997. p. 101-125.

[Recebido em outubro de 2005 e aceito para publicação em abril de 2006]

\begin{abstract}
Production of Knowledge in a 'Problematic' World: Contributions of a Dialectical and Relational Feminism

Abstract: This artic le describes a dvances in feministepistemology that began with the perception of science as binary and androcentric, which revealed the mutually-constituting relationship between the subjects of science and the knowledge they produce. This understanding, establishing the possibility of combating deterministic and binary science through the analysis of the production of knowledge as a social and historical process, also revealed the ideological nature of the social world. The authors discussed construct a critical, dialectical and relational perspective which aims to illuminate how 'differences' a re articulated in systemic relations of domination, and to transform this 'problematic' world.
\end{abstract}

Key Words: Feminist Epistemology; Social Studies of Science; Id eology; Dialectics. 